ăn 3 bữa/ngày, 2 bữa/ngày (35.4\%), 1 bữa/ngày (4.4\%). Người bênh ăn ít hơn chiếm tỷ lệ nhiều hơn số người bệnh ăn nhiều hơn $(82.4 \%$ và $13.2 \%)$. Chủ yếu trong giai đoạn trầm cảm người bệnh phần lớn bị giảm và mất cảm giác ngon miệng, tỷ lệ tăng ngon miệng chiếm số ít. Có đến 64,7\% người bệnh có phong cách ăn uống không lành manh, trong đó tỷ lệ người bệnh ăn uống thất thường theo cảm xúc chiếm cao nhất là $50.0 \%$. Vì vâyy, các triệu chứng ăn uống rất thường gặp ở giai đoạn trầm cảm. Cần chú ý đến nhóm triệu chứng này để phát hiện và điêu trị sớm để cải thiện tình trạng bệnh và nâng cao chất lượng cuộc sống của người bệnh.

\section{TÀI LIÊU THAM KHẢO}

1. World Health Organization. MSD-MER. Depression and other common Mental disorders: Global Health Estimates; 2017.2

2. Nguyễn Trọng Hiến. Nghiên Cứu Đặc Điểm Đau ở Bênh Nhân Rối Loan Trâm Cảm Điều Trị Nội Trú Tai Viện Sức Khỏe Tầm Thần. Luận văn tổt nghiệp Bác sỹ̃ Nội trú. Đại học Y Hà Nội; 2016.

3. Nguyễn Văn Dũ̉ng. Nghiên Cứu Đặc Điểm Lâm Sàng Trầm Cảm Khới Phát ở Người Cảo Tuổi. Luận án Tiến sỹ Y hoc; 2013.

4. Husain MM, Rush AJ, Sackeim HA, et al. Agerelated characteristics of depression: a preliminary STAR*D report. Am J Geriatr Psychiatry Off J Am Assoc Geriatr Psychiatry. 2005;13(10):852-860. doi:10.1176/appi.ajgp.13.10.852

5. Lazarevich I. Depression and food consumption in Mexican college students. Nutr Hosp. Published online May 10, 2018. doi:10.20960/nh.1500

\title{
ĐÁNH GIÁ KẾT QUẢ ĐIỀU TRI VÀ MộT Số YẾU TỐ LIÊN QUAN TRÊN BỆNH NHÂN UNG THƯ TỤY GIAI ĐOẠN MUQ̣̂N TẠI BỆNH VIỆN K
}

\section{TÓM TẮT}

Mục tiêu: Đánh giá kết quả điều trị và một số yếu tố liên quan trên bệnh nhân ung thư tụy giai đoạn muộn tại Bệnh viện K. Đối tượng: 154 bệnh nhẩn được chẩn đoán ung thư biểu mô tụy giai đoạn tiến triển tại chố hoặc di căn xa được chia làm 3 nhóm: điều trị hóa chất có thể kèm theo phẫu thuật hoặc can thiệp thủ thuật chăm sóc giảm nhẹ; nhóm không điều trị hóa chất được phẫu thuật, can thiệp CSGN và nhóm không điêu trị tại bệnh viện K. Kết quả: Trong nhóm 38 bệnh nhân không điều trị có trung vị thời gian sống thêm toàn bộ là 3.3 tháng (khoảng tin cậy 95\% là 2.9-3.7 tháng). Trong 22 bệnh nhân không điều trị hóa chất được phẫu thuật, can thiệp CSGN có trung vị thời gian sống thêm toàn bộ là 3.9 tháng (khoảng tin cậy 95\% là 3.1-4.8 tháng). Trong 94 bệnh nhân có điều trị hóa chất: Không có đáp ứng hoàn toàn và tỉ lệ đáp ứng 1 phần là $17 \%$, bệnh giữ nguyên là $37.2 \%$, bệnh tiến triên là $45.7 \%$. Trung vị thời gian sống thêm bệnh không tiến triển là 3.9 tháng (khoảng tin cậy $95 \%$ là 3.3-4.5 tháng). Trung vị thời gian sống thêm toàn bộ là 8.2 tháng (khoảng tin cậy $95 \%$ là $6.5-$ 9.8 tháng). Tổng số chu kì hóa chất được điều tri ở 94 bệnh nhân trong nghiên cứu là 381 chu kì. Về độc tính hóa chất: $\mathrm{Ha}$ bach cầu trung tính độ 3-4 gặp ở 10.2\% số bệnh nhân. Hạ tiểu cầu độ 3-4 gặp ở 6.9\% số bệnh nhân. Ha huyết sắc tố độ 3-4 gặp ở 7.6\% số bệnh

\footnotetext{
${ }^{1}$ Trường Đại học Y Hà Nội

2Bệnh viện $K$ trung ương

Chiu trách nhiệm chính: Hoàng Minh Lý

Email: hoangminhly3107@gmail.com

Ngày nhân bài: 3.8.2021

Ngày phản biện khoa học: 1.10.2021

Ngày duyệt bài: 7.10.2021
}

\section{Hoàng Minh Lý ${ }^{1}$, Đào Văn Tú ${ }^{2}$}

nhân. Tăng men gan độ 3 gặp ở 4.2\% số bệnh nhân. Không ghi nhận tăng men gan độ 4 .

Tư khóa: Ung thư tụy, Phẫu thuật/thủ thuật chăm sóc giảm nhẹ, Thời gian sống thêm bệnh khổng tiến triển, Thời gian sống thêm toàn bộ.

\section{SUMMARY}

\section{THE EFFICACY OF TREATMENT IN STAGE} III AND IV AND SOME FACTORS RELATED WITH THE PANCREATIC CANCER AT K HOSPITAL

Objectives: To evaluate the efficacy of treatment in stage III, IV and some factors related with the pancreatic cancer at $\mathrm{K}$ hospital. Patients and methods: 154 patients diagnosed with locally advanced or metastatic pancreatic cancer at K hospital were divided into 3 groups: chemotherapy group may be accompanied by palliative surgical procedures; the non-chemotherapy group received palliative surgical procedures; and untreated patients' group. Result: In the group of 38 untreated patients, the median overall survival was 3.3 months (95\% confidence interval 2.9 to 3.7 months). In 22 non-chemotherapy patients who underwent Palliative surgical procedures had a median overall survival of 3.9 months (95\% CI 3.1-4.8 months). In 94 patients receiving chemotherapy: We found that none of patient showed a complete response, the partial response rate was $17 \%, 37.2 \%$ of the patients were stable and $45.7 \%$ of the patients had progressive disease. The median progression-free survival was 3.9 months (95\% confidence interval, 3.3 to 4.5 months). The median overall survival was 8.2 months (95\% confidence interval, 6.5 to 9.8 months). Three hundred ninety-one cycles were administered with 154 patients, grade 3-4 toxicity per patient was $10.2 \%$ for neutropenia, $6.9 \%$ for thrombocytopenia, $7.6 \%$ for hematological toxicities, $6.9 \%$ for anemia. 
grade 3 for $4.2 \%$ alanine aminotransferase or aspartate aminotransferase. No patient had grade 4 for alanine aminotransferase or aspartate aminotransferase.

Keyword: Pancreatic cancer, Palliative surgical procedures, Progression-free survival, Overall survival.

\section{I. ĐẶT VẤN ĐỀ}

Ung thư tụy là 1 ung thư rất ác tính, có nguồn gốc từ các tế bào của mô tụy, trong đó hơn 95\% là ung thư biểu mô tuyến tụy xuất phát từ phần tụy ngoại tiết và được gọi là ung thư tụy ngoại tiết, $5 \%$ còn lại phát triển từ tế bào đảo tụy thuộc tụy nội tiểt và được xếp vào nhóm u thần kinh nội tiểt [1]. Trên thế giới ung thư tụy đứng thứ 7 trong các nguyên nhân gây tử vong do bệnh ung thư (300.000 ca tử vong trong tổng số 338.000 ca mới mắc) [2]. Tại Mỹ, tỉ suất mắc mới của ung thư tụy đứng thứ 9 ở nam và thứ 10 ở nữ. Tỉ lệ tử vong cao hơn, xếp thứ tư ở cả 2 giới [2]. Ung thư tụy có tỷ lệ sống sau 5 năm thấp nhất (5-6\%) và kì vọng sống ngắn nhất (6 tháng) khi so sánh với các bệnh ung thư khác [3].

Tại Việt Nam, ung thư tụy đứng thứ 12 về tỉ suất mắc mới $(2.6 / 100.000)$ và tî lệ tử vong (1.0/100.000). Một số yếu tố nguy cớ gây ung thư tụy: yếu tố di truyền, hút thuốc lá, béo phì, đái tháo đường, nghiện rượu, viêm tụy.... [3] Với những tiến bộ của y học hiện đại, việc chẩn đoán ung thư tụy đã có nhiều cải thiện, tuy nhiên do triệu chứng bệnh nhân thường xuất hiện muộn, khồng điển hình nên $80 \%$ bệnh nhân được chẩn đoán ở giai đoạn không còn khả năng phẫu thuật triệt căn [1], [2]. Với ung thư tụy giai đoạn muộn (III,IV) hóa chất toàn thân là phương pháp điêuu trị cơ bản với mục đích giảm nhẹ triệu chứng và cải thiện thời gian sống thêm [1]. Ngoài ra thì điều trị chăm sóc giảm nhẹ triệu chứng ngày càng được quan tâm như giải quyết tình trạng tắc mật và hẹp môn vị cho bệnh nhân. Tại Việt Nam hiện nay ung thư tụy có nhiều thay đổi trong điều trị, để có nhìn nhận tổng quan bệnh nhân ung thư tụy được điều trị như thế nào và yếu tố nào ảnh hưởng đến tiên lượng của bệnh nhân Cần thiết phải có một đánh giá tiên lượng phù hợp và một lộ trình điều trị hiệu quả nhằm kéo dài thời gian sống thêm trên bệnh nhân. Vì vậy, nghiên cứu này được thực hiện nhằm mục tiếu đánh giá kết quả điều trị và một số yếu tố liên quan trên bệnh nhân ung thư tụy giai đoạn muộn tại Bệnh viện $\mathrm{K}$.

\section{II. ĐỐI TƯợNG VÀ PHƯƠNG PHÁP NGHIÊN CứU}

1.Đối tượng nghiên cứu. Bệnh nhân ung thư tụy giai đoạn không còn khả năng phẫu thuật triệt căn được chẩn đoán và điều trị tại bệnh viện $K$ từ tháng 1/2017 đến tháng 6/2021.

Tiêu chuẩn lựa chọn: Các bệnh nhân ung thư tụy có tuổi $\geq 18$ được chẩn đoán ung thư tụy ngoại tiết qua kết quả mô bệnh học (sinh thiết u tụy hoặc vị trí di căn), trong khoảng thời gian từ tháng $1 / 2017$ đến tháng $6 / 2021$ giai đoạn tiến triển tại chỗ hoặc di căn xa (theo AJCC 2018), chỉ số toàn trạng từ 0-2.

Trong nhóm bệnh nhân điều trị hóa chất: chưa điều trị hóa chất trước đó có tổn thương đích đánh giá được theo tiêu chuẩn RECIST 1.1 [4], được điều trị ít nhất 2 chu kì hóa chất và được theo dõi sau điều trị.

Tiêu chuẩn loại trừ: Bệnh nhân mắc các bệnh cấp tính đe dọa tính mạng, hoặc các bệnh nhân có di căn thần kinh trung ương, phụ nữ có thai, bệnh nhân mắc ung thư thứ 2 .

\section{Phương pháp nghiên cứu}

Thiết kế nghiên cứu: Nghiên cứu mô tả phân tích kết hợp hồi cứu và tiến cứu.

Cỡ mẫu: Theo công thức tính cỡ mẫu theo kết quả nghiên cứu của Wang và cộng sự [5]. 154 bệnh nhân đủ tiêu chuẩn lựa chọn từ tháng 1/2017 đến tháng 6/2021 được đưa vào nghiên cứu.

Quá trình điêu trị: 3 nhóm bệnh nhân

Nhóm 1: 94 bệnh nhân điều trị hóa chất phác đồ đơn chất, 2 thuốc hoặc kết hợp 3 thuốc có thể kèm theo phẫu thuậ̣t hoặc can thiệp thủ thuật CSGN.

Nhóm 2: 22 bệnh nhân điều trị bằng phẫu thuật hoặc can thiệp CSGN: nối mật ruột, dẫn lưu đường mật, nối vị tràng.

Nhóm 3: 38 bệnh nhân nhóm không điều trị.

Đánh giá độc tính của phác đồ: Độc tính trên huyết học và cơ quan gan, thận (Theo NCICTCAE 5.0)

Đánh giá đáp ứng điêu trị: sau 2-4 chu kì, theo RECIST 1.1 gồm: Đáp ứng hoàn toàn, Đáp ứng 1 phần, Bệnh ổn định, Bệnh tiến triển.

Đánh giá thời gian sống thêm bệnh không tiến triển (PFS): là khoảng thời gian từ lúc bệnh nhân bắt đâu được điều trị cho tới thời điểm xác định bệnh tiến triển hoặc bệnh nhân tử vong.

Đánh giá thời gian sống thêm toàn bộ (OS): cho cả 3 nhóm bệnh nhân, là khoảng thời gian từ lúc bệnh nhân bắt đầu được điều trị cho tới thời điểm bệnh nhân tử vong vì bất kì nguyên nhân gì.

\section{KẾT QUẢ NGHIÊN CỨU}

1.Một số đặc điểm của đối tượng nghiên cứu. Kểt quả cho thấy trong tổng số 154 bệnh nhân tham gia nghiên cứu, nam giới chiếm tî lệ 
$57.8 \%$, nữ giới chiếm tỉ lệ $42.2 \%$. Tỉ lệ nam/nữ là 1.5/1. Tuổi trung bình của các đối tượng nghiên cứu là 59.1, thấp nhất là 31 tuổi, cao nhất là 82 tuổi. Tỉ lệ bệnh nhân có tăng CA19.9 là $78.6 \%$, tỉ lệ bệnh nhân có CA19.9>500 là $43.5 \%$. Tỉ lệ bệnh nhân ở giai đoạn tiến triển tại chỗ là $37 \%$ và ở giai đoạn di căn là $63 \%$. Trong số các bệnh nhân di cằn, tỉ lệ di căn gan là $80.4 \%$. Lý do vào viện chính của các bệnh nhân là đau bụng chiếm tî lệ $75.3 \%$, vàng da chiếm $18.8 \%$, gầy sút cân chiếm $3.2 \%$, khám định kì phát hiện bệnh chiếm $2.7 \%$.

2.Độc tính của nhóm điêu trị hóa chất

Có tổng số 381 chu kì hóa chất của 94 bệnh nhân được điều trị trong nghiên cứu đều được ghi nhận độc tính qua từng chu kì điều trị dựa trên CTCAE bản 5.0. Kết quả thu được độc tính trên hệ tạo huyết và chức năng gan thận/ $\mathrm{Ha}$ bạch cầu trung tính độ 3-4 gặp ở 10.2\% số bệnh nhân. Hạ tiểu cầu độ 3-4 gặp ở 6.9\% số bệnh nhân. Hạ huyết sắc tố độ 3-4 gặp ở $7.6 \%$ số bênh nhẩn. Tăng men gan độ 3 gặp ở $4.2 \%$ số bệnh nhân. Không ghi nhận tăng men gan độ 4 .

3.Đáp ứng với điêu trị và 1 số yếu tố liên quan. Trong nghiên cứu của chúng tôi, không có bệnh nhân nào đạt được đáp ứng hoàn toàn. và tî lệ đáp ứng 1 phần là $17 \%$ (16/94 bệnh nhân), bệnh giữ nguyên đạt 37.2\% (35/94 bệnh nhân), và bệnh tiến triển chiếm $45.7 \%$ (43/94 bệnh nhân). Mối liên quan giữa đáp ứng điều trị với 1 số yếu tố được trình bày trong bảng 1 : tỉ lệ đáp ứng ở giai đoạn 3 cao hơn so với giai đoạn 4 sự khác biệt có ý nghĩa thống kê $(p<0.05)$, tỉ lệ đáp ứng ở nhóm điều trị từ 4 chu kì hóa chất trở lên cao hơn so với nhóm dưới 4 chu kì, sự khác biệt có ý nghĩa thống kê $(p<0.05)$. Tỉ lệ đáp ứng ở nhóm bệnh nhân có u ở đầu tụy và nhóm u ở thân đuôi tụy là không có sự khác biệt ( $p>0.05)$.

Bảng 1: Môi liên quan giữa tỉ lệ đáp ứng với vị trí u, giai đoạn bệnh, số chu kì hóa chất, giai đoạn bệnh ban đâuu

\begin{tabular}{|c|c|c|c|c|c|}
\hline & \multicolumn{2}{|c|}{ Bênh đáp ứnq hoăc qiữ nquyên } & \multicolumn{2}{|c|}{ Bênh tiến triến } & \multirow[t]{2}{*}{$\mathbf{P}$} \\
\hline & $n 1$ & $\%$ & n2 & $\%$ & \\
\hline \multicolumn{5}{|l|}{ Số chu kì điều trị } & \multirow{3}{*}{$p<0.05$} \\
\hline$*_{>}>3$ chu kì & 42 & 44.7 & 8 & 8.5 & \\
\hline$* \leq 3$ đơt & 9 & 9.6 & 35 & 37.2 & \\
\hline Tống & 9 & 30 & 21 & 70 & \\
\hline \multicolumn{6}{|l|}{ Vị trí u } \\
\hline *U đầu tụy & 25 & 26,6 & 20 & 21.3 & $p>0.05$ \\
\hline *U thân đuối tụy & 26 & 27.7 & 23 & 24.5 & \\
\hline Tống & 9 & 30 & 21 & 70 & \\
\hline \multicolumn{6}{|c|}{ Giai đoạn bệnh ban đâu } \\
\hline *'Giai đoạn 3 & 26 & 27.7 & 12 & 12.8 & $\mathrm{P}<0.05$ \\
\hline *Giai đoạn 4 & 25 & 26.6 & 31 & 33.0 & \\
\hline Tống & 9 & 30 & 21 & 70 & \\
\hline
\end{tabular}

4.Thời gian sống thêm của bệnh nhân Thời gian sống thêm mà bệnh không tiến triển (PFS). Kết quả cho thấy trung vị thời gian sống thêm bệnh không tiến triển là 3.9 tháng. Độ tin cậy 95\%: 3.3-4.5 tháng.
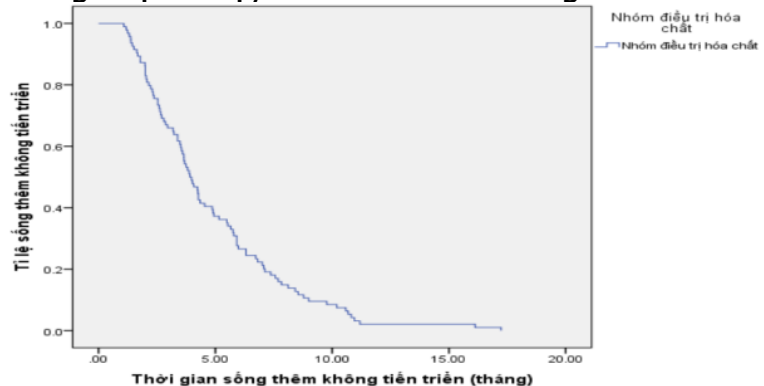

Biểu đồ 1: Thời gian sống thêm bệnh không tiến triển (PFS)

Thời gian sống toàn bộ (OS) ở nhóm hóa chất. Kết quả cho thấy trung vị thời gian sống thêm toàn bô ở nhóm hóa chất là 8.2 tháng. Độ tin cậy 95 là 6.5-9.8 tháng.

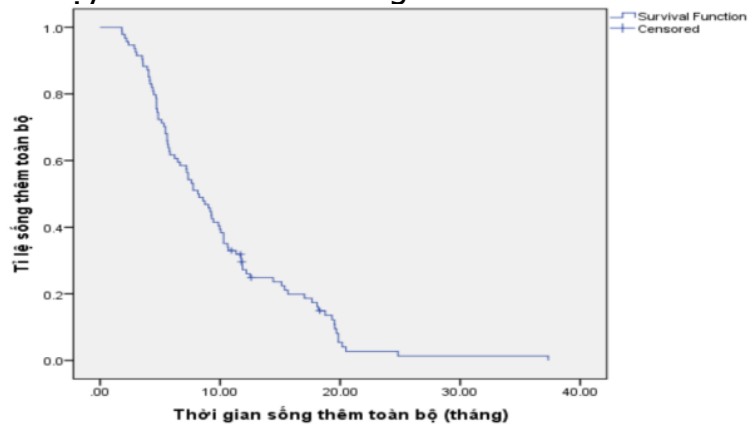

Biểu đồ 2: Thời gian sông thêm toàn bộ (OS) ở nhóm hóa chất

Thời gian sống toàn bộ (OS) ở cả 3 nhóm. Kết quả cho thấy trung vị thời gian sống thêm nhóm điều trị CSGN là 3.9 tháng. Độ tin cậy 95 là 3.1-4.8 tháng. Nhóm không điều trị có 
trung vị thời gian sống thêm là 3.3 tháng. Độ tin cậy 95\% là 2.9-3.7 tháng.

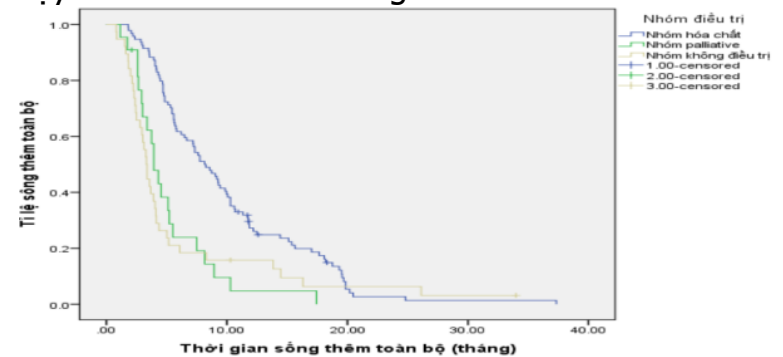

Biêu đồ 3: Thời gian sống thêm toàn bộ (OS) ở cả 3 nhóm.

Thời gian sống toàn bộ (OS) theo giai đoạn bênh

Bảng 2: Sông thêm theo giai đoạn bệnh ơ nhóm điều trị hóa chất

\begin{tabular}{|c|c|c|}
\hline Giai đoạn bệnh & $\begin{array}{c}\text { Tiến triển } \\
\text { tại chô̂́ } \\
\text { (n1=36) }\end{array}$ & $\begin{array}{c}\text { Giai đoạn } \\
\text { di căn xa } \\
\text { (n2=53) }\end{array}$ \\
\hline $\begin{array}{c}\text { Trung vị thời gian } \\
\text { sống thêm toàn } \\
\text { bộ (tháng) }\end{array}$ & 10.3 & 5.6 \\
\hline$p$ & \multicolumn{2}{|c|}{0.001} \\
\hline
\end{tabular}

Kết quả cho thấy trung vị thời gian sống thêm toàn bộ ở nhóm tiến triển tại chỗ cao hơn nhóm di căn xa, sự khác biệt là có ý nghĩa thống kê với $\mathrm{p}<0.05$

Thời gian sống toàn bộ (OS) với điêuu trị hóa chất sau phác đồ thứ nhất.

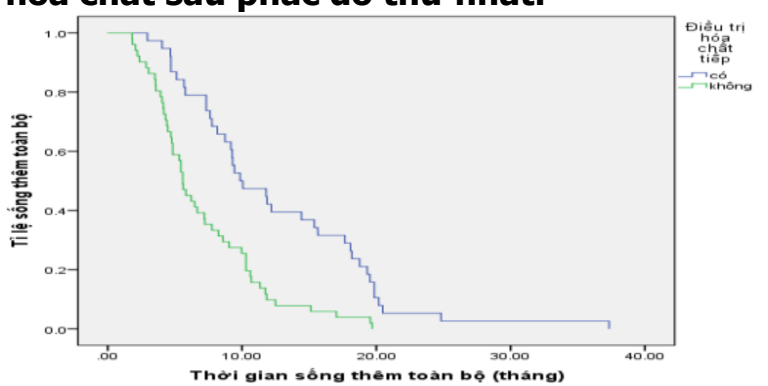

Biểu đồ 4: Sống thêm toàn bộ với điều trị hóa chât tiếp theo.

Kết quả cho thấy ở nhóm có điều trị hóa chất tiếp sau phác đồ đâu tiên có trung vị thời gian sống thêm toàn bộ là 9.9 tháng cao hơn nhóm không điều trị tiếp là 5.6 tháng, khác biệt có ý nghĩa thống kề với $p<0.05$.

\section{BÀN LUÂ̂N}

Kết quả nghiên cứu cho thấy không có trường hợp đáp ứng hoàn toàn sau điều trị, tỉ lệ bệnh nhân có đáp ứng với điều trị hoặc bệnh giữ nguyên chiếm tới $61,2 \%$. thấp hơn nghiên cứu của Heinemann và CS(2006) với tỉ lệ là $57.5 \%$ [6]. Theo nghiên cứu, tỉ lệ đáp ứng của giai đoạn
3 cao hơn so với giai đoạn 4 và sự khác biệt này là có ý nghĩa thống kê. Tỉ lệ đáp ứng ở nhóm điều tri từ 4 chu kì hóa chất trở lên cao hơn so với nhóm $\leq 3$ chu kì, sự khác biệt có ý nghĩa thống kê. Như vậy giai đoạn lúc mới chẩn đoán, số chu kì hóa chất được điều trị là 1 yếu tố tiên lượng đáp ứng với hóa chất điều trị. Trong nhóm 94 bệnh nhân điêu trị hóa chất có trung vị thời gian sống thêm bệnh không tiến triển là 3.9 tháng, trong đó bệnh nhân có tiến triển nhanh nhất là 1.3 tháng từ lúc bắt đâu điều trị hóa chất và bệnh nhân tiến triển chậm nhất là 17.2 tháng (trong nghiên cứu của chúng tôi có 5 bệnh nhân đang tiếp tục điều trị chưa thây bệnh tiến triển). Kết quả này tương tự của 2 nghiển cứu: nghiên cứu GIP-1, Cunningham và CS (2009) với kết quả lần lượt là 3.9 tháng [7], [8]. Trung vị thời gian sống thêm toàn bộ ở nhóm hóa chất là 8.2 tháng. Trung vị thời gian sống thêm toàn bô ở nhóm bệnh nhân giai đoạn tiến triển tại chố là 10.3 tháng cao hơn nhóm di căn xa là 4.5 tháng, sự khác biệt là có ý nghĩa thống kê với $p=0.001$. Đồng thời, nhóm có điều trị hóa chất tiếp sau phác đồ đầu tiên có trung vị thời gian sống thêm toàn bộ cao hơn nhóm không điều trị với kết quả lần lượt là 9.9 và 5.6 tháng, khác biệt có ý nghĩa thống kê với $p<0.000$. Về độc tính hóa chất: Hạ bạch câu trung tính độ 3-4 gặp ở 10.2\% số bệnh nhân. Hạ tiểu câuu độ 3-4 gặp ở $6.9 \%$ số bệnh nhân. Hạ huyết sắc tố độ 3-4 gặp ở 7.6\% số bệnh nhân. Tằng men gan độ 3 gặp ở $4.2 \%$ số bệnh nhân. Không ghi nhận tăng men gan độ 4 . Kết quả trung vị thời gian sống thêm nhóm điều trị CSGN là 3.9 tháng. Nhóm không điêu trị có trung vị thời gian sống thêm là 3.3 tháng. Trung vị thời gian sống thêm toàn bộ bệnh nhân là 5.6 tháng.

\section{KẾT LUÂ̂N}

Nghiên cứu đã thể hiện được thực tế trong điều trị ung thư tụy giai đoạn muộn tại việt Nam. Điều trị hóa chất giúp cải thiện sống thêm cho bệnh nhân ung thư tụy giai đoạn này và nêu ra một số yếu tố liên quan đến OS, đáp ứng điều trị. Kết quả này có thể liên quan đến nhân chủng học, số lượng bệnh nhân trong nghiên cứu và điều kiện kinh tế, khả năng chăm sóc bệnh nhân giai đoạn cuối tại Việt Nam.

\section{TÀI LIÊU THAM KHẢO}

1. Nguyễn Bá Đức, Trân Văn Thuấn, Nguyễn Tuyết Mai (2010). Ung thư tưy. Điểu trị nội khoa bệnh ung thư. Nhà xuất bản Y học, 189 - 199

2. Ferlay J., Soerjomataram I., Dikshit R. và cộng sự. (2015). Cancer incidence and mortality worldwide: sources, methods and major patterns in GLOBOCAN 2012. Int J Cancer, 136(5), E359-386. 
3. Genkinger J.M., Spiegelman D., Anderson K.E. và công sư. (2009). ALCOHOL INTAKE AND PANCREATIC CANCER RISK: A POOLED ANALYSIS OF FOURTEEN COHORT STUDIES. Cancer Epidemiol Biomark Prev Publ Am Assoc Cancer Res Cosponsored Am Soc Prev Oncol, 18(3), 765-776.

4. Eisenhauer E.A., Therasse P., Bogaerts J. và cộng sự. (2009). New response evaluation criteria in solid tumours: Revised RECIST guideline (version 1.1). Eur J Cancer, 45(2), 228-247.

5. Wang Yi, Xiao Xiuying, et al. (2018), "A Survival Model in Locally Advanced and Metastatic Pancreatic Ductal Adenocarcinoma", Journal of Cancer, 9(7), pp. 1301-1307.

6. Heinemann V., Quietzsch D., Gieseler F. và cộng sự. (2006). Randomized phase III trial of gemcitabine plus cisplatin compared with gemcitabine alone in advanced pancreatic cancer. J Clin Oncol Off J Am Soc Clin Oncol, 24(24), 3946-3952.

7. Cunningham D., Chau I., Stocken D.D. và cô̂ng sự. (2009). Phase III randomized comparison of gemcitabine versus gemcitabine plus capecitabine in patients with advanced pancreatic cancer. J Clin Oncol Off J Am Soc Clin Oncol, 27(33), 5513-5518.

8. Colucci G, Roberto Labianca et al (2010), "Randomized phase III trial of Gemcitabine plus Cisplatin compared with Single-Agent Gemcitabine as First-line treatment of patients with advanced pancreatic cancer: The GIP-1 study", J Clin Oncol, 28, pp 1645-1651.

\section{KẾT QUẢ PHẪU THUÂT U TUYẾN GIÁPLÀNH TÍNH TẠI BÊ̂NH VIỆN ĐẠI HỌC Y HÀ NộI}

\section{TÓM TẮT}

Muc tiêu: Đánh giá kết quả phẫu thuật nội soi (PTNS) đường nách vú trong điêu tri u tuyến giáp lành tính tai Bệnh viên Đai học Y Hà Nô̂i. Đối tượng và phương pháp: Nghiên cứu mô tả hồi cứutrên 90 bệnh nhân chẩn đoán u tuyến giáp lành tính được phẫu thuât mở (45 bênh nhân) hoăc PTNS đường nách vú (45 bệnh nhân) cắt thùy hoặc cắt thùy và eo tuyễn giáp tại Bênh viên Đaii hoc Y Hà Nôi từ01/2019 đến 06/2019. Kết quả: Trung bình là $51,4 \pm 12,8$ tuổi

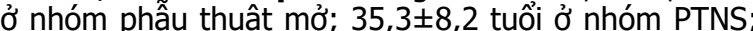
$91,1 \%$ nữ giới; tỳ lệ 1 u trên lâm sàng $80 \%$ ở nhóm phẩu thuât mở và $71,1 \%$ ở nhóm PTNS; u thùy phải $52,8 \%$ ở nhóm phẫu thuật mở và 59,4\% ở nhóm PTNS; kích thước u trung bình $25,9 \pm 10,1 \mathrm{~mm}$ ở nhóm phẫu thuật mở và $23,7 \pm 9,8 \mathrm{~mm}$ ở nhóm PTNS. Trên siêu âm, u TIRADS 3 chiếm $77,8 \%$ ở cả hai nhóm. Giải phẫu bệnh sau mổ bướu giáp keo chiếm $82,2 \%$ ơ nhóm phấu thuât mở và $84,4 \%$ ở nhóm PTNS. Cắt thuỳ tuyến giáp ở 73,3\% trường hợp trong nhóm phẫu thuật mở và ở 97,8\% trường hợ trong nhóm PTNS. Thời gian mổ trung bình $41,7 \pm 10,2$ phút ở nhóm phẫu thuât mở và $51,2 \pm 7,1$ phút ở nhóm PTNS; thời gian hậu phẫu $5,8 \pm 1,3$ ngày ở nhóm phẫu thuật mở và $6,0 \pm 1,2$ ngày ở nhóm PTNS. Không có trường hợp nào PTNS chuyển phâuu thuật mở. Không có biến chứng sau mổ ở nhóm phấu thuật mở, nhóm PTNS có 1 trường hợp $(2,2 \%)$ tu máu sau mổ, hết sau băng ép 1 ngày. Đau nhe sau mổ chiếm $62,2 \%$ trường hợp ở nhóm phẫu thuật mở và $82,2 \%$ trường hợp ở nhóm

\footnotetext{
${ }^{1}$ Trường Đại học Y Hà Nội

2Bênh viên Đai hoc Y Hà Nôi

Chịu trách nhiệm chính: Lê Văn Thắng

Email: lethanghmu@gmail.com

Ngày nhận bài: 2.8.2021

Ngày phản biên khoa họ: 1.10 .2021

Ngày duyệt bài: 8.10.2021
}

\section{Lê Văn Thắng1, Nguyễn Xuân Hậu ${ }^{2}$}

PTNS, không có trường hợp nào đau nặng sau mổ.0 bệnh nhân đánh giá không hài lòng về kết quả phẫu thuật, tî lệ rất hài lòng chiếm $75,6 \%$ ở nhóm phẫu thuất mở và $80 \%$ ở nhóm PTNS. Kết luân: Phẫu thuật mở và PTNS đường nách vú trong điều trị u tuyển giáp lành tínhtương đối an toàn, tỳ lệ tai biến, biến chứng thấp trong đó PTNS ít đau sau mổ hơn và đạt thẩm mỹ cao so với phẫu thuâtt mở.

Tư khóa: U giáp trạng, lành tính, phẫu thuật mở, phẫu thuật nội soi.

\section{SUMMARY \\ RESULTS OF THYROIDECTOMY FORBENIGN THYROID NODULEAT HANOI MEDICAL UNIVERSITY HOSPITAL}

Objective: Evaluate theearly results ofendoscopic thyroidectomy via unilateral axillo-breast approach (UABA) in the treatment of benign thyroid tumor at Hanoi Medical University Hospital. Subjects and Methods: Descriptive retrospective studies 90 patients with benign thyroid tumors were treated (lobectomy or lobectomy+ismuthsectomy) byopen thyroidectomy (45 patients) and byUABA (45 patients) at Hanoi Medical University Hospital from 01/2019 to $06 / 2019$. Results: Mean of age was $51,4 \pm 12,8$ years in the open thyroidectomy group; $35,3 \pm 8,2$ years in the UABA group. $91,1 \%$ patients were female. The solitary tumor occults $80 \%$ in the open thyroidectomy group and $71,1 \%$ in the UABA group;thethyroid tumors in the right lobe were $52,8 \%$ in the open thyroidectomy group and $59,4 \%$ in the UABA group; the average tumor size was $25,9 \pm 10,1 \mathrm{~mm}$ in the open thyroidectomy group and $23,7 \pm 9,8 \mathrm{~mm}$ in the UABA group. The tumors classified into TIRADS 3 by ultrasound was $77,8 \%$ in both groups. Most common pathology was colloid goitreaccounting for $82,2 \%$ in the open thyroidectomy group and $84,4 \%$ in the UABA group. Lobectomy was applied in $73,3 \%$ cases in the open thyroidectomy group and $97,8 \%$ cases in the 